\title{
Corticosteroid inhibition of thermogenesis in obese animals
}

By David A. York, Department of Human Nutrition, School of Biochemical and Physiological Sciences, University of Southampton, Bassett Crescent East, Southampton SO9 3TU

The wide range of animal models that have been used for the study of obesity may be classified into four major types according to the origin of that obesity, i.e. genetic, dietary, endocrine or that following hypothalamic damage (Bray \& York, 1979). The ability to prevent the further development of obesity by adrenalectomy is a common feature between these models (Hausberger \& Hausberger, 1960; Mook et al. 1972; Bray, 1982; Bruce et al. 1982; Holt et al. 1983; Marchington et al. 1983, 1986; Rothwell et al. 1984; Saito \& Bray, 1984; Saito et al. 1985; Debons et al. 1986; Freedman et al. 1986; Tokunaga et al. 1989). Bruce et al. (1982) were the first group to report this effect, in rats developing obesity after electrolytic lesions to the ventromedial hypothalamus. While the effect of adrenal status is most pronounced in the obesities, subsequent observations have shown a similar role of the adrenal in the control of energy balance in lean animals.

Brown adipose tissue (BAT) thermogenesis is thought to play an important role in the control of energy balance in the rodent species, in addition to its accepted role in the maintenance of body temperature during exposure to cold environments (Rothwell \& Stock, 1984). Part of the evidence for this has been the demonstration of impaired diet-related BAT function in the obesities, and the coincident restoration of normal energetic efficiency and normal BAT function after adrenalectomy (Trayhurn \& James, 1978; Marchington et al. 1983, 1986; Rohner-Jeanrenaud et al. 1983; Knehans \& Romsos, 1984; Allars et al. 1987). These relations can be illustrated by studies on the obese Zucker ( $f a / f a$ ) rat. BAT mitochondrial GDP binding of $f a / f a$ rats, an index of mitochondrial thermogenic activity, is reduced from an early age in the preobese falfa rat (Bazin et al. 1984; Holt et al. 1984). After weaning, the BAT progressively develops the appearance of an hypoactive tissue as mitochondrial content, GDP binding and uncoupling protein (UCP) concentration are reduced, while triacylglycerol deposits increase (Holt et al. 1983; Triandafillou \& Himms-Hagen, 1983; Bazin et al. 1984; Allars et al. 1987). Adrenalectomy rapidly restores both the morphological appearance and the function of the tissue to normal; mitochondrial content, GDP binding and UCP concentration increasing to levels observed in lean rats. Replacement of adrenalectomized falfa rats with glucocorticoids, but not aldosterone, reverses all these effects of adrenalectomy and restores the development of obesity (Holt et al. 1983; Freedman et al. $1985,1986)$. The obesity of the falfa rat has been attributed, in part at least, to the impairment in the normal metabolic response to feeding (Rothwell et al. 1983, 1984). Thus, the acute increase in oxygen consumption that follows a meal is impaired in the falfa rat, as are the chronic responses to giving extra sucrose, or cafeteria, high-fat and low-protein diets (Holt et al. 1983; Triandafillou \& Himms-Hagen, 1983; Allars et al. 1987). Both the acute and chronic responses are corrected after adrenalectomy. Likewise, the adaptive changes in BAT function that normally occur on overfeeding are greatly attenuated in obese falfa rats, but are restored after adrenalectomy (Holt $e t$ al. 1983; Marchington et al. 1983; Rothwell et al. 1984).

Similar changes to those described previously have also been reported in other forms of genetic obesity, in particular in the obese $(o b / o b)$ and diabetic $(d b / d b)$ mice, and in the obesity resulting from hypothalamic damage (Cox \& Powley, 1977; Trayhurn, 1979; 
Rohner-Jeanrenaud et al. 1983; Saito \& Bray, 1984; Hogan et al. 1985; Smith \& Romsos, 1985). In addition, it is now clear that adrenal status also affects BAT function and energetic efficiency in lean rats (Rothwell \& Stock, 1984; Rothwell et al. 1984). The effect is most clearly demonstrated in the old cafeteria-fed rat in which the agedependent loss of adaptive response to the diet is prevented by adrenalectomy (Rothwell et al. 1984). The effect of adrenalectomy may be limited to animals fed on diets in which carbohydrate provides the major energy component, and may only be partial when very-high-fat diets are provided (Smith \& Romsos, 1985; Bray et al. 1989).

Glucocorticoids are required for normal BAT non-shivering thermogenesis (Fellenz et al. 1982), yet these same hormones appear to inhibit BAT diet-related thermogenesis. Such evidence suggests that BAT per se is not the primary site of glucocorticoids in controlling BAT function, a suggestion which is supported by the reports of normal BAT response to noradrenaline stimulation in obese rats where diet-related (Holt et al. 1984) but not cold-related BAT thermogenesis is impaired. Some impairment in the sympathetic drive to BAT, as measured by tissue noradrenaline turnover, has been demonstrated in all animal models of obesity that have been studied (Van der Tuig et al. 1982; Niijima et al. 1984; Yoshimatsu et al. 1984; Romsos, 1985; Bray et al. 1989). Indeed, the normal response to cold acclimation in the obese rat and the absence of response to dietary stimuli correlate with the effects of these stimuli on sympathetic activity. Likewise, the restoration of BAT responses to dietary signals after adrenalectomy of falfa rats and $o b / o b$ mice has been associated with increased sympathetic drive to BAT (Van der Tuig et al. 1984; York et al. 1985). Recently, we (Holt \& York, 1989a) have been able to confirm the reduction in sympathetic drive to BAT of obese rats by direct measurement of the electrical activity of the nerves innervating the interscapular BAT pad. Cannon \& Nedergaard (1986) have postulated that the $\alpha_{1}$-adrenergic pathway has an important role in BAT hyperplasia and growth, probably through effects on the thyroxine $5^{\prime}$-deiodinase (EC 3.8.1.4) enzyme. This hypothesis is supported by our observations (Raasmaja \& York, 1988) in obese rats that $\alpha_{1}$-adrenergic receptor density on brown adipocytes was reduced, but restored to normal levels by either adrenalectomy or cold acclimation, but not dietary stimuli. Thus, it would appear that the increase in sympathetic drive to BAT that results from the removal of glucocorticoid initiates a complex series of responses that leads to the restoration of normal morphological appearance and function of the tissue.

Changes in circulating glucocorticoid levels initiate reciprocal effects in pituitary adrenocorticotrophic hormone (ACTH) secretion and hypothalamic corticotrophinreleasing factor (CRF) production. It is then pertinent to ask which, if any, of these hormones or neuropeptides is responsible for the described effects of adrenal status on sympathetic drive to BAT. Any potential role for ACTH may be discounted for two reasons: first, hypophysectomy has a similar effect to adrenalectomy in preventing obesity (Powley \& Morton, 1976), while second, corticosterone replacement to hypophysectomized obese rats restores the defects in BAT function, food intake and energetic efficiency (Holt et al. 1988a). Thus, attention has been directed towards understanding the possible role of glucocorticoid-CRF interaction in the control of obesity, and in particular in the control of sympathetic activity to BAT. The demonstration that a single injection of a glucocorticoid into the lateral ventricle of adrenalectomized gold-thioglucose-obese mice would temporarily restore weight gain and excess food intake (Debons et al. 1986) is suggestive of a central effect of glucocorticoids. CRF is widely distributed in the brain and has been identified in a number of hypothalamic centres known to function in the control of energy balance (Brown et al. 1982). CRF given intracerebroventricularly (icv), either acutely or chronically, suppresses food intake (Levine et al. 1983; Arase et al. 1988), enhances sympathetic activity (Brown \& 
Fisher, 1985; Arase et al. 1988) and depresses parasympathetic activity (Tache \& Gunion, 1985). A lack of CRF function would provide an attractive hypothesis to explain the defects in a number of obese models and the restoration of normal energetic efficiency and BAT function after adrenalectomy. We have recently shown that CRF given icv will increase the firing rate of sympathetic nerves innervating the interscapular BAT pad in a dose-dependent manner in both lean and obese ( $f a l f a)$ rats, but that the maximal response to CRF remains substantially reduced in the obese rat (York et al. 1988; Holt \& York 1989b). Thus, CRF alone appears to be unable to mimic the effects of adrenalectomy, and the possibility must be considered that other neuropeptides, whose secretion is sensitive to glucocorticoid removal, are involved. Chronic infusions of CRF given icv into obese rats will, however, prevent further weight gain and reduce insulin levels (York et al. 1988). However, the question remains as to whether impaired CRF activity can be implicated in the development of obesity, or whether adrenalectomy, through its stimulation of CRF and other neuropeptide secretion, may provide a compensatory mechanism which can override the defective control of energy balance.

Glucocorticoids regulate the response of the sympathetic nervous system to dietrelated signals, and this effect appears to be most prominent in animals fed on high-carbohydrate diets (Smith \& Romsos, 1985). Several independent lines of evidence now suggest an interaction between glucocorticoids and carbohydrate-related aspects of energy balance. Liebowitz et al. (1985) have demonstrated the presence of a glucocorticoid-dependent $\boldsymbol{\alpha}_{1}$-adrenergic system for carbohydrate feeding in the paraventricular nucleus (PVN) of rats. The PVN is also the site of CRF-containing neurons which control ACTH secretion from the pituitary (Sawchenko et al. 1984). However, it is unlikely that the PVN is the major site for any glucocorticoid control of diet-related thermogenesis, since it has not been possible to demonstrate any functional connection between the PVN and sympathetic nerves innervating BAT (Holt et al. 1988b), and since the obesity observed after lesions of the PVN is also prevented by adrenalectomy (Tokunaga et al. 1988). Likewise, the ventromedial hypothalamus is unlikely to be the site of action of glucocorticoids or CRF in controlling energy balance, since the effect of adrenalectomy is still observed in obesity resulting from damage to this region (Bruce et al. 1982).

2-Deoxy-D-glucose (2-DOG) is a glucoprivic agent which has multiple actions in the central nervous system. Among these are the stimulation of feeding and the suppression of sympathetic drive to BAT, both effects of which are absent in the obese ( $\mathrm{fa} / \mathrm{fa}$ ) rat but are restored after adrenalectomy (Ikeda et al. 1980; Allars \& York, 1986; York et al. 1988). Conversely, glucocorticoids will suppress these effects of 2-DOG in lean rats. Finally we have shown (Holt \& York, 1989a; York et al. 1988) that obese (falfa) rats have an attenuated sympathetic response to acute injections of glucose into the third ventricle, consistent with their impaired response to changes in dietary intake. Thus, we may propose the hypothesis that the glucocorticoid or CRF actions may be on the lateral hypothalamus (LH). Lesions of the LH stimulate sympathetic activity (Yoshida et al. 1983). Furthermore, the activity of glucose-sensitive cells in this region is inhibited by glucose (Oomura, 1983). A glucocorticoid inhibition (CRF stimulation) of such cells might provide the mechanism underlying the effects of glucocorticoid status on sympathetic responses, as outlined in Fig. 1.

While the site of, and mechanism through which, glucocorticoids affect BAT function are still unknown, it is clear that (1) the glucocorticoid effects are mediated through changes in the sympathetic drive to the tissue, (2) the effect is specific to diet-related sympathetic activity and is mediated centrally, and (3) changes in CRF production or activity, or both, may play an important role in mediating the response to alterations in glucocorticoid status. 


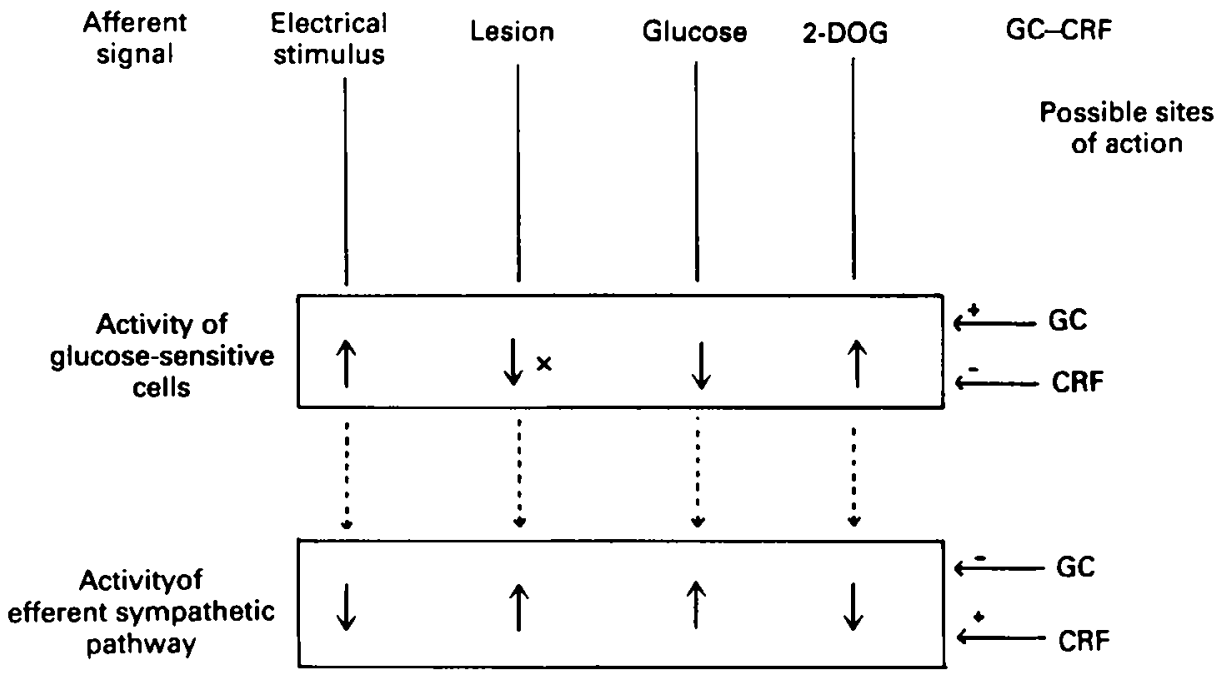

Fig. 1. Hypothetical sites of action of glucocorticoid (GC) in regulating diet-related sympathetic activity. The hypothesis envisages that reduced activity of glucose-sensitive cells in the lateral hypothalamus leads to the removal of an inhibitory influence and stimulation of the efferent sympathetic pathway. Glucocorticoids are envisaged as either activating cells at the lateral hypothalamic level or inhibiting the sympathetic pathway efferently. $\uparrow$, Increased activity; $\downarrow$, decreased activity; $\times$, activity abolished; - , inhibitory; + , stimulatory. CRF, corticotrophin-releasing hormone; 2-DOG, 2-deoxy-D-glucose.

\section{REFERENCES}

Allars, J., Holt, S. J. \& York, D. A. (1987). International Journal of Obesity 11, 591-602.

Allars, J. \& York, D. A. (1986). International Journal of Obesity 10, 147-158.

Arase, K., York, D. A., Shimizu, H., Shargill, N. S. \& Bray, G. A. (1988). American Journal of Physiology 255, E255-E259.

Bazin, R., Eteve, D. \& Lavau, M. (1984). Biochemical Journal 221, 241-245.

Bray, G. A. (1982). Proceedings of the Nutrition Society 41, 95-108.

Bray, G. A. \& York, D. A. (1979). Physiological Reviews 59, 719-809.

Bray, G. A., York, D. A. \& Fisler, J. S. (1989). Vitamins and Hormones (In the Press).

Brown, M. R. \& Fisher, L. A. (1985). Federation Proceedings 44, 243-248.

Brown, M. R., Fisher, L. A., Spiess, J., Rivier, J., Rivier, C. \& Vale, W. (1982). Endocrinology 111, 928-931.

Bruce, B. K., King, B. M., Phelps, G. R. \& Veitia, M. C. (1982). American Journal of Physiology 243, E152-E157.

Cannon, B. \& Nedergaard, J. (1986). In Proceedings of the 13th International Congress of Nutrition, pp. 315-319 [T. G. Taylor and N. K. Jenkins, editors]. London: John Libbey.

Cox, J. E. \& Powley, T. L. (1977). Joumal of Comparative Physiology and Psychology 91, 347-358.

Debons, A. F., Zuerk, L. D., Tse, C. S. \& Abrahmsen, S. (1986). Endocrinology 118, 1678-1681.

Fellenz, M., Triandafillou, J., Gwilliam, C. \& Himms-Hagen, J. (1982). Canadian Journal of Biochemistry 60, 838-842.

Freedman, M. R., Castonguay, T. W. \& Stern, J. S. (1985). American Journal of Physiology 249, R584-R594. Freedman, M. R., Horwitz, B. A. \& Stern, J. S. (1986). American Journal of Physiology 250, R595-R607.

Hausberger, F. X. \& Hausberger, R. (1960). American Journal of Clinical Nutrition 8, 671-678.

Hogan, S., Himms-Hagen, J. \& Coscina, D. V. (1985). Physiology and Behavior 35, 287-294.

Holt, S. J., Rothwell, N. J., Stock, M. J. \& York, D. A. (1988a). American Journal of Physiology 254, E162-E166.

Holt, S. J. \& York, D. A. (1989a), Brain Research 481, 106-112. 
Holt, S. J. \& York, D. A. (1989b). Physiology and Behavior 45 (In the Press).

Holt, S. J., York, D. A. \& Fitzsimons, J. T. R. (1983). Biochemical Journal 214, 215-223.

Holt, S. J., York, D. A., Rothwell, N. J. \& Stock, M. J. (1984). American Journal of Physiology 246, E391-E396.

Hoit, S. J., Wheal, H. V. \& York, D. A. (1988b). Neuroscience Letters 84, 63-67.

Ikeda, H., Nishikawa, K. \& Matsuo, T. (1980). American Journal of Physiology 239, E379-E384.

Knehans, A. W. \& Romsos, D. R. (1984). Journal of Nutrition 114, 2080-2088.

Liebowitz, S. F., Brown, O., Tretter, J. R. \& Kirschgessner, A. (1985). Pharmacology and Biochemistry of Behaviour 23, 541-550.

Levine, A. S., Rogers, B., Kneip, J., Grace, M. \& Morley, J. E. (1983). Neuropharmacology 22, 337-339.

Marchington, D., Rothwell, N. J., Stock, M. J. \& York, D. A. (1983). Journal of Nutrition 113, 1395-1402.

Marchington, D., Rothwell, N. J., Stock, M. J. \& York, D. A. (1986). American Journal of Physiology 250, E362-E366.

Mook, D. G., Kennedy, N. J., Roberts, S., Nusbaum, A. I. \& Rodier, V. I. (1972). Journal of Comparative Physiology and Psychology 81, 198-211.

Niijima, A., Rohner-Jeanrenaud, F. \& Jeanrenaud, B. (1984). American Journal of Physiology 247, R650-R654.

Oomura, Y. (1983). Advances in Metabolic Diseases 10, 31-65.

Powley, T. L. \& Morton, S. (1976). American Journal of Physiology 230, 982-987.

Raasmaja, A. \& York, D. A. (1988). Biochemical Journal 249, 831-838.

Rohner-Jeanrenaud, F., Seydoux, J., Chinet, A., Baa, S., Giacobina, J.-P., Assimacopoulos-Jeannet, F., Jeanrenaud, B. \& Girardier, K. (1983). Journal of Physiology, Paris 78, 833-837.

Romsos, D. R. (1985). International Journal of Obesity 9, 55-62.

Rothwell, N. J., Saville, M. E. \& Stock, M. J. (1983). American Joumal of Physiology 244, R615-R620.

Rothwell, N. J. \& Stock, M. J. (1984). Recent Advances in Physiology 10, 349-384.

Rothwell, N., Stock, M. J. \& York, D. A. (1984). Comparative Biochemistry and Physiology 78A, 565-569.

Saito, M. \& Bray, G. A. (1984). American Journal of Physiology 246, R20-R25.

Saito, M., Minokoshi, Y. \& Shimazu, T. (1985). American Journal of Physiology 248, E20-E25.

Sawchenko, P. E., Swanson, L. W. \& Vale, W. W. (1984). Proceedings of the National Academy of Science, USA 81, 1883-1887.

Smith, C. K. \& Romsos, D. R. (1985). American Journal of Physiology 249, R13-R22.

Tache, Y. \& Gunion, M. (1985). Federation Proceedings 44, 255-258.

Tokunaga, K., Fukushima, M., Lupien, J. R., Bray, G. A., Kemnitz, J. W. \& Schemmel, R. (1989). Physiology and Behavior 45 (In the Press).

Trayhurn, P. (1979). Pfligers Archiv 380, 227-232.

Trayhurn, P. \& James, W. P. T. (1978). Pfiugers Archiv 373, 189-193.

Triandafillou, J. \& Himms-Hagen, J. (1983). American Journal of Physiology 244, E145-E150.

Van der Tuig, J. G., Knehans, A. W. \& Romsos, D. R. (1982). Life Sciences 30, 913-920.

Van der Tuig, J. G., Ohshima, K., Yoshida, T., Romsos, D. R. \& Bray, G. A. (1984). Life Sciences 34, 1423-1432.

York, D. A., Hoit, S. J., Allars, J. \& Payne, J. (1988). In Obesity in Europe 1988, pp. $247-252$ [P. Bjorntorp and S. Rossner, editors]. London: John Libbey.

York, D. A., Marchington, D., Holt, S. J. \& Allars, J. (1985). American Journal of Physiology 249, E299-E305.

Yoshida, T., Kemnitz, J. W. \& Bray, G. A. (1983). Journal of Clinical Investigation 72, 919-927.

Yoshimatsu, H., Niijima, A., Oomura, Y., Yamabe, K. \& Katafuchi, T. (1984). Brain Research 303, 147-152. 